\title{
The nexus between money growth and inflation in Turkey: New evidence from a Wavelet Analysis
}

Turgut Tursoy ( $\nabla$ turgut.tursoy@neu.edu.tr)

Near East University https://orcid.org/0000-0002-6404-5748

Muhammad Mar'i

Near East University

Research

Keywords: Money supply, inflation, wavelet analysis, Turkey, the quantity theory of money

Posted Date: February 21st, 2020

DOI: https://doi.org/10.21203/rs.2.24250/v1

License: (9) This work is licensed under a Creative Commons Attribution 4.0 International License. Read Full License 


\title{
The nexus between money growth and inflation in Turkey: New evidence from a Wavelet Analysis
}

1. Turgut Tursoy (Corresponding Author)

Head, Department of Banking and Finance, Near East University, North Cyprus, Mersin 10 Turkey, email: turgut.tursoy@neu.edu.tr

2. Muhammad Mar'i

PhD Student, Department of Banking and Finance, Near East University, North Cyprus, Mersin 10 Turkey, email: mr9466@yahoo.com

\begin{abstract}
The study investigates the lead-lag relationship in Turkey by employing wavelet analysis, mainly continuous wavelet analysis, cross wavelet transforms and wavelet coherence and phase-difference, during the period from 1987 to 2019. Our finding confirms the existing relationship between money supply and inflation, and also showing a different pattern for the structure of the relationship between money supply and inflation; moreover, the result corresponds with the fact that Turkey experienced many economic crises during the period. Additionally, the results show that the lead-lag relationship between money supply and inflation is changeable and the inflation leads as a result of the Demand-pull theory. The result is consistent with the traditional quantity theory of money in the long run, and; also regarding the modern quantity theory of money, there is also short-run and long-run relationship between money supply and inflation.
\end{abstract}

Keywords: Money supply, inflation, wavelet analysis, Turkey, the quantity theory of money. 


\section{Introduction}

The importance of inflation as a macroeconomic factor in the literature is derived from its capacity to represent monetary policy's efficiency and effectiveness in affecting the macroeconomy. Specifically, the degree to which inflation influences production growth or economic conditions has proven to be a subject of significant importance to any Central Bank regarding price stability. Generally, the empirical evidence appears to lend support to the idea that inflation is counterproductive to economic growth and that price stability, described as a low and stable inflation rate, at least it is an essential prerequisite for achieving economic growth (Mavikela, Mhaka, \& Phiri, 2019).

In the case of Turkey, the country experienced many events and economic crises, particularly after the 1999 earthquake, where the inflation rate rose to $70 \%$ as the country went into recession, despite the policies and programs that Turkey pursued to contain inflation and the signing of a new agreement with the International Monetary Fund (IMF). However, at the beginning of 2001, the Turkish government announced that an economic crisis was suffocating the country due to the large volume of external debt, and the Turkish government was close to bankruptcy (Tursoy, 2019). The monetary policy was quick to develop new programs and strategies to target inflation, together with the IMF; and in line with these reforms, in the year 2005, 6 zeros were removed from the local Turkish currency, and was changed to the "New Turkish Lira" (Bankası, 2005).

Turkish plans related to targeting inflation were subjected to many deviations, particularly in the years 2009 and 2010 as a result of the 2008 mortgage crisis, as global production and demand decreased, and the rise in oil prices affected Turkey as the country is an oil importer (DURMUŞ, 2018). At the end of 2010, the Turkish Central Bank established new monetary policies that would reduce Turkey's vulnerability to external shocks, and set policies that took into account price stability along with financial stability (Kayıkçı \& Kaplan, 2019).

The nature of the relationship between money supply and inflation in Turkey is not entirely clear due to the limited amount of studies that have focused on this subject and the lack of methods that have taken time-frequency into account. To the best of the authors' knowledge, this is the first study that has attempted to determine the lead-lag relationship between the growth in money supply and inflation directly using timefrequency.

To investigate the nexus between money supply and inflation rate, also providing new insights into this relationship, this study employs wavelet analysis. One of the features of wavelet analysis is that it reveals information in time-frequency that cannot be obtained by analyzing time series. We also employ cross wavelet analysis and phase deference to determine the lead-lag relationship.

Inflation refers to the situation where more money is paid for the same goods or services. Although it is possible to determine whether an economy is suffering from inflation, there is no consensus in the literature regarding the cause of this phenomenon. Hence 
Keynesian economists explain the relationship between money supply and inflation, they provide the explanations via "demand-pull" and "cost-push" type and Demand-pullinflation. Monetarists suggest that inflation occurs as a result of an increase in the money supply (Abdullah, Al-Abduljader, \& Naser, 2020). As central banks are primarily focused on maintaining price stability, money flows have been given less importance increasingly. However, it seems that there might less interest in literature to concerns the money supply go hands in hands with inflation to keeping inflation down and steady (King, 2001).

Money growth has a long-term impact on inflation, as promoted by the quantity theory of money, where growth price levels precede an increase in the money supply. However, empirical evidence on the connection between money growth and inflation and the effectiveness of money to forecast inflation remains controversial (Vladova \& Yanchev, 2015).

Milton Friedman argued that inflation is fiscal and monetary policy should be concerned with efforts to reduce the inflation rate in a country, especially when the inflation is the first anchor. Consequently, as generally believed, an increase in the money supply is to have a significant long-term effect on the economic activity of any country (Ditimi, Sunday, \& Emma-Ebere, 2017).

The monetary authority may make a significant contribution to fostering economic stability by establishing a steady course and ensuring that it remains focused on this. Ensuring that the increase in the amount of money is steady but modest would make a significant contribution to preventing and inflation or price deflation. However, governmental policies aimed at increasing spending and attempting to achieve full employment, as well as attempts that are made by the Central Bank, are the primary causes of an increase in the money supply, which causes inflation (Friedman, 1968). It has enormous importance that policymakers ensure the financial stability that is needed for low inflation and sustainable economic growth in the first place and those policies which are combat with inflation are ensuring the stability in the economy.

This paper is structured as follows. Section 2 provides a literature review and previous studies on the relationship between money supply and inflation. Section 3 explains the methodology used in this study. Section 4 describes the data and discusses the results, while the conclusion is presented in Section 5 .

\section{Literature Review}

The monetary theory claims that inflation occurs when the money supply increases more than money demand. On the other hand, changes in income and price are driven by money. Researchers interested in studying the nexus between money supply and inflation have generally used the most famous version of the quantity equation of exchange formulated by Fisher (1911). The Fisher and Brown (1911) equation is expressed as: 
$\mathrm{M}\left(\mathrm{V}_{\mathrm{T}}\right) \equiv \mathrm{P}_{\mathrm{T}}(\mathrm{T})$

Where $\mathrm{M}$ is money in circulation, $\mathrm{V}_{\mathrm{T}}$ is the transaction velocity of circulation, $\mathrm{P}_{\mathrm{T}}$ is the average price level of transaction, and $\mathrm{T}$ is the total transactions per period. The left-hand side symbolizes money supply while the right side symbolizes money demand. A higher supply of money leads to a higher amount of price and vice versa. Consequently, a shift in the supply of money will lead to a change in prices. In other words, if a country faces high inflation rates, decreasing the amount of money supply will reduce inflation and vice versa, and this situation is disinflation and deflation (Ditimi et al., 2017). The relationship between money supply and inflation are linked with money demand, and money supply, where the expenditure surplus that is not met by increasing output will lead to an increase in price since the rise in expenditure changes the price rather the quantity (Strano, 2003)

Fisher and Brown (1911) assumed that, as monetary authorities increase the level of currency (money supply) in the market, deposits must increase by the same ratio, while the velocity and quantity of goods remain constant. This is expressed by as:

$\mathrm{M}(\overline{\mathrm{V}})=\mathrm{P}(\overline{\mathrm{Y}})$

Changing the supply of money given the constancy of velocity and output will result in equivalent proportionate inflation rate changes ( $\mathrm{Su}, \mathrm{Fan}$, Chang, \& $\mathrm{Li}, 2016)$. However, many economists argue that Monterey's theory does not meet in the short-run, and it focuses on the long-run properties of the economy rather than short-run dynamics. Additionally, monetarists are sceptical about the potential of using monetary policy to achieve short-term stability (Meyer, 2001).

To explain the relationship between money and inflation, many researchers have studied the relationship between them by using different methods. The researchers' findings differ according to the country and method of analysis. Next, we will briefly review some studies about the nexus between money supply and inflation.

Abdullah et al. (2020) attempted to identify the determinants of inflation in Kuwait during the period 1979 to 2015 to examine whether inflation is affected by the exchange rate, interest rate, taxation, current account, unemployment, GDP and money supply using multiple regression analysis. The study results showed that the change in the inflation rate was significantly affecting on money supply, and its impact was positive.

Ditimi et al. (2017) investigated the effects of money supply on inflation in Nigeria using a co-integration autoregressive dynamic error correction model approach. The findings showed that the money supply has no significant effect on inflation in both the short run and long run, while the Granger causality test indicates that there was a causality between money supply and inflation in bi-direction during the study period of 1970 to 2016. In contrast, Sasongko \& Huruta (2018) found a unidirectional causality between money supply and inflation rate by using the Granger causality method, but not vice versa. The study aimed to determine the causal relationship between money supply and inflation in Indonesia during the period 2007 to 2017. 
Jiang et al. (2015) investigated the relationship between money supply and inflation rate in China during the period from the mid-1990s to the early 2000 s using novel wavelet analysis. The study results support the modern quantity theory of money, which indicates that money growth and the inflation rate are positively related, although in the short run, there are deviations from such a positive relation due to temporary shocks. Su et al. (2016) also examined the relationship between money supply and inflation rate in China by using bootstrap Granger full sample causality and sub-sample rolling causality. The study aimed to check whether the Chinese economy supported the quantity theory of money. The varying rolling-window approach employed in this research showed that the money supply has a positive and negative impact on inflation in several sub-periods, and vice versa, the finding of the study is consistent with the modern quantity theory of money. Jiang et al. (2015) used wavelet analysis and found that money growth had a positive impact on inflation in China with some deviations. The study results confirmed the modern quantity theory of money.

Vladova and Yanchev (2015) examined the relationship between dynamic money supply (currency in circulation, M1, M2) and prices in Bulgaria during the period 1998 to 2012 using three econometric methods, namely dynamic cross-correlations, Granger causality test in the framework unrestricted VAR models and Johansen cointegration. The study concluded that there was a two-way relationship between money supply and price dynamics.

Nguyen (2015) investigated the effect of fiscal deficit and broad money supply (M2) on inflation in nine Asian countries over the period 1985 to 2012 using the pooled mean group estimation based on error correction model and generalised method of moments. The main finding was that the money supply (M2) had a positive impact on inflation in the pooled mean group method.

Regarding Turkey, Koyuncu (2014) investigated the impact of the budget deficit and Money supply (M2) on inflation using Johansen cointegration and Granger causality during the period from 1987 to 2013. The Granger causality showed a unidirectional relationship from Money supply to inflation, but it was not indicated that the direct cause of inflation is the money supply. Additionally, the Johansen test revealed that there was no cointegration between the series.

Rua (2012) investigated the relationship between money growth and inflation over the period 1970 to 2007 in the euro area using wavelet analysis. The study results revealed a strong association between money supply and inflation in the short term (low frequency) and this relationship getting stronger at long term development than short term fluctuation of the business cycle. 


\section{Methodology}

This section presents the methodology used in the study, namely wavelet analysis, including continuous wavelet transform, cross wavelet transforms and wavelet coherence. Wavelet analysis has become a popular tool in analysing time series due to its ability to provide a better understanding of data in both time-domain analysis and frequency domain analysis.

Information on the time series is not always sufficient to gain an insight into the data. Sometimes, the data's frequency also involves significant data information. The Fourier transformation (FT) measures the frequency-amplitude of the data in the time domain, but it does not indicate when this frequency has occurred in time. All frequency components take place at any point in time in the case of stationary data, but this is not true for non-stationary data. FT, therefore, is not suitable for non-stationary data, so wavelet analysis is used as an alternative for Fourier transformation. Wavelet analysis can handle nonstationary data and has the ability to provide information in both time and frequency simultaneously (Jeet \& Vats, 2017).

The continuous wavelet transform (CWT) is considered as a useful tool for extracting information from the time series and data with the self-similarity detection. the CWT produces many wavelet coefficients $\mathrm{C}$, which can represent a function of two factors: scale and position $C$ (scale,position). A specific wavelet $\psi$ is obtained by projection onto the tested time series $\mathrm{x}(\mathrm{t})$

$$
C(\text { scale }, \text { position })=\int_{-\infty}^{\infty} x t \psi(\text { scale, } \text { position }, t) d t
$$

any value consonant with the region of the time series $\mathrm{x}(\mathrm{t})$ could be taken in scale and position. Multiplying each coefficient by the fittingly scaled (dilated) and shifted wavelet produces the constituent wavelets of the authentic signal. There are several types of wavelets, with various properties for different applications. Since in the analysis of both the amplitude and phase information, this study is interested with the most popular wavelet one which is Morlet wavelet which is defined as;

$$
\psi_{\eta}(t)=\pi^{-\frac{1}{4}} e^{i w 0 \eta}-e^{-\frac{\eta^{2}}{2}}
$$

Where is $w$ the frequency of the angle (rotation rate per time unit), which is set at a value of 6 as recommended in the literature, the normalisation term is $-1 / 4$ is the dimensionless time parameter represented by $\eta=t / \lambda$, $t$ is the time parameter, and $\lambda$ is the scale of the wavelet. The process of scaling and shifting is described below. (Gençay, Selçuk, \& Whitcher, 2001; In \& Kim, 2013; Loh, 2013)

Cross wavelet analysis and wavelet coherence are considered as powerful techniques for testing suggested linkages between two-time series. The continuous wavelet transform 
can be extended to include time series and construct a cross wavelet transformation, which identifies areas with high joint influence and provides more detail on the phase association (Grinsted, Moore, \& Jevrejeva, 2004). When the two wavelet transformations being performed are in reference to the same mother wavelet, then the transformation of the cross wavelet shows the degree of the commonality between the two initial wavelet transforms or signals. To deduce the existence of a mutual signal or locate the source of these common signals can be used by the magnitude' of the cross wavelet transform. The similarity may occur for various reasons, and each implementation may give different justifications for this commonality; the magnitude of the cross wavelet transform will have a peak that shows this similarity (Randy \& Young, 1993).

In this paper, to avoid biased results as well as any incorrect distortions or deviation by giving more weight to large-scale linking phenomena than to small-scale phenomena, corrected wavelet transformation is used by normalizing the scale as follows:

$$
w x y(t, s)=\frac{1}{s} \cdot w x(t, s) \cdot \bar{w} y(t, s)
$$

For more details on the suggested cross-wavelet bias-corrected by normalizing scales, see Veleda et al. (2012)

For the phase differences, we follow Rösch and Schmidbauer (2016) and write:

$$
\operatorname{Angle}(\mathcal{T}, \mathcal{S})=\operatorname{Arg}(\text { Wave. } x y(\mathcal{T}, \mathcal{S}))
$$

This so-called x-over-y phase difference at each time and scale is equal to the difference between individual local phase separations when transformed into an interval angle $[-\pi, \pi]$. The two series are considered in-phase (anti-phase) if the absolute value is less (or higher) than $\pi / 2$ at the scale. Fig. 1 in Appendix 1 presents an interpretation of the phase differences.

Wavelet coherence is another useful measure to determine how coherent the cross wavelet transform is in time-frequency space (Grinsted, Moore, \& Jevrejeva, 2004, p. 564) and demonstrates how powerful the co-movement between two series is over time and frequency and it locates between zero and one, as we closer to one as we have more powerful association, in addition to the degree of the relation, the wavelet coherency plot indicate at which frequencies the association locate. (Özmen \& Yllmaz, 2017) For analyzing the wavelet coherence between two-time series, we follow Torrence and Webster (1998) and write:

$$
R_{n}^{2}(s)=\frac{\left|s\left(s^{-1} w_{n}^{x y}(s)\right)\right|^{2}}{s\left(s^{-1}\left|w_{n}^{x}(s)\right|^{2}\right) s\left(s^{-1}\left|w_{n}^{Y}(s)\right|^{2}\right)}
$$

The smoothing operator is $\mathrm{S}$ is a suitable smoothing operator for the Morlet wavelet and is given by 
$\left.s_{\text {time }}(w)\right|_{s}=\left(w_{n}(s) * c_{1} \frac{-t 2}{s^{2}}\right) \mid$,

$\left.s_{\text {time }}(w)\right|_{s}=\left(w_{n}(s) * c_{2} \Pi(0.6 s)\right) \mid$,

Where the normalisation constants are $\mathrm{c} 1$ and $\mathrm{c} 2$ and $\prod$ are the rectangle function, the factor of 0.6 is the empirically determined scale decorrelation length for the Morlet wavelet.

For the phase differences, we follow Rösch and Schmidbauer (2016) and write:

$$
\operatorname{Angle}(\mathcal{T}, \mathcal{S})=\operatorname{Arg}(\text { Wave. } x y(\mathcal{T}, \mathcal{S}))
$$

This so-called x-over-y phase difference at each time and scale is equal to the difference between individual local phase separations when transformed into an interval angle $[-\pi, \pi]$. The two series considered in-phase (anti-phase) if the absolute value is less (or higher) than $\pi / 2$ at the scale. Fig. 1 in Appendix 1 presents an interpterion of the phase differences.

\section{Data and result}

For analysing the nexus and lead-lag relationship between growth inflation (IN) and money growth (Narrow Measure (M1), Intermediate Measure (M2), Broad Measure (M3)), monthly data are obtained from the Turkish Central Bank. The data cover the period between February 1987 until October 2019, and the data is monthly percent change. No adjustment is made on the original data since the study data is growth rate (percent) and the wavelet transform can handle nonstationary data, meaning that it is not necessary to test for a unit root or take any difference. Fig. 2. in Appendix B. show the plots for all variables. It can be observed that there was a substantial deviation in inflation in 1994, which is when a currency crisis occurred in Turkey, as well as a significant deviation in M1 and M2 in 2005, which is the year when the Turkish currency converted to the New Turkish Lira.

Table.1 in Appendix C. shows descriptive statistics of the variables. It can be observed that the inflation fluctuated between $-1 \%$ and $23 \%$ with a mean of 0.03 and a standard deviation of 0.03 . The growth in money supply rates shows an extensive range of fluctuation. For instance, M1 has a minimum of $-20.19 \%$, and a maximum of $68.2 \%$ with a mean of 3.39 and a standard deviation of 7.98 These fluctuations are explained by a series of major crises in Turkey during the period of the study.

Before analysing the lead-lag relationship between money inflation and money supply, we start by applying the continuous wavelet transform to capture the vital information that occurred in frequency Fig. 3 shows the results of the continuous wavelet transform of both inflation and money supply at different time horizons. The INF plot has many 
large significant plots at different times and frequencies. One fascinating significant region is located around 1994, which is the year of the Turkish currency crisis, and it can be seen that the effect of the crisis in high frequency and extended to reach more than 32 periods.

IN

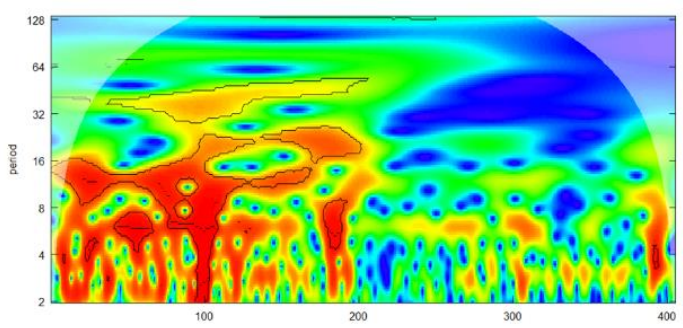

M2

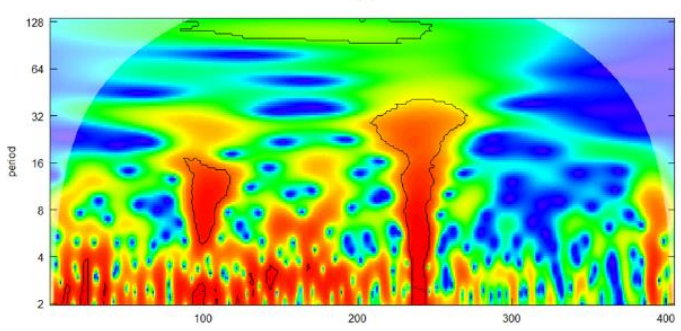

M1

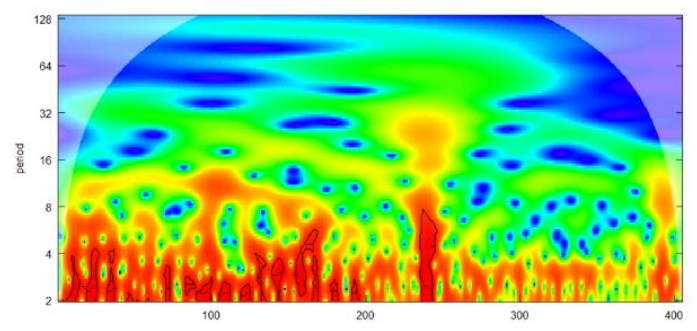

M3

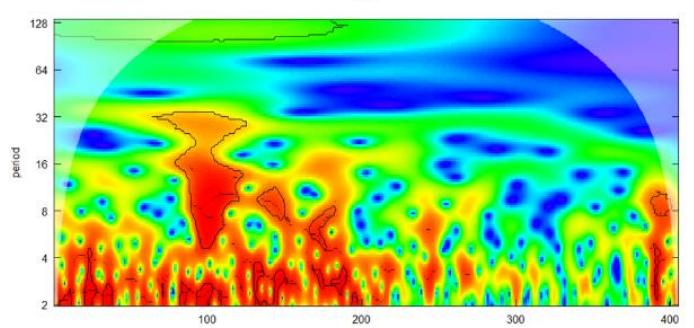

\begin{tabular}{|l|l|}
\hline 100 & $5 /$ \\
& 1994 \\
\hline 200 & $9 /$ \\
& 2002 \\
\hline 300 & $1 /$ \\
& 2011 \\
\hline 400 & $\begin{array}{l}5 / \\
2019\end{array}$ \\
\hline
\end{tabular}

Fig. 3. Continuous wavelet transforms for the study variables. Note: $5 \%$ significance level against red noise designates by the contour, and the lighter shade shows the cone of influence. Power colour code ranges from blue (low power) to red (high power).

As a result of the currency crisis that occurred in 1994, the output fell by 6 percent, inflation increased to three-digit levels, the central bank lost half of its reserves, and in the first quarter of the year, the exchange rate (against the US dollar) depreciated by more than half (Celasun, 1999). Another significant plot region can be observed around 2001, which was when the Turkish government was close to announcing bankruptcy as a result of its deficit (Tursoy, 2019).

The effect of the crisis in 2001 was not as severe as the crisis of 1994, which is clear from Fig. 3 it extended for years at low frequency (around 16 months and 32 months). The last significant region located at high frequency was around 2018, which represents the fall of the Turkish lira against the US dollar by $40 \%$ as a result of the currency crisis in 2018.

Regarding the money supply, it is evident in Fig 3. that M3 was the most affected by the currency crisis in 1994, as its effect can clearly be observed from month 4 to month 32. On the other hand, M2 was the most affected by the mortgage crisis in 2008, as we can see a significant plot region extending from high frequency (month 2) and to low frequency (month 32). M1 shows many significant regions from 1987 to around 2008, where the tremendous effect on the money supply was caused by the global economic crisis in 2008. 
"The cross wavelet transform indicates the extent of commonality between the two original wavelet transforms or signals" (Randy \& Young, 1993, P 110). In order to identify the similarity of change between time-series signals together, we employed cross wavelet analysis. Fig.4. shows the cross wavelet analysis for the pair of IN-M1, in which we can observe significant plots from 1987 until around 1994 at different frequencies. Around before the 1990s, there are significant plots for the pairs at high frequency (up to around 5 month), the common region out of phase-based that the arrow left-oriented, since the arrows left upward which mean money supply growth leading while inflation lagging, another significant plot also around before the 1990 os we can see two significant regions at high frequency, the first up to 5 months we can see money supply leading and the second around 6 months it's clear that the M1 lagging while IN leading. The most significant plot region is located around 1994, where there are two separate significant plots, the first of which is at high frequency (from 2 to around 5). In this plot region, we can see that IN is leading and M1 is lagging, which indicates that inflation led to the currency crisis in 1994 in the short run. At frequency 5 to around month 15, it is not clear which one is leading the currency crisis and which one was lagging, but it still appears that the pair move together.

As shown in Fig. 4, the IN-M2 IN-M3 pairs are similar to the IN-M1 with minimal differences. However, there is a large significant plot region around 1994 at low frequency (around 25 to around 50) that does not appear in IN-M1. It appears that in this pair (INM1) that the leading inflation while M2, M3 lagging after neutral significant plot region in 1994 which it's not clear which variable was leading and which one lagging, the significant plot region in 1994 is more massive for the IN-M3 pair than for INF-M2. We can see another plot region during the study period, but it is not clear which is leading and which is lagging. 


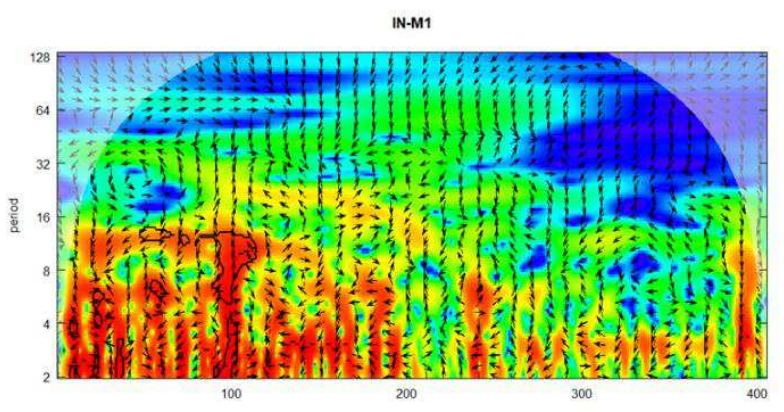

\begin{tabular}{|l|l|}
\hline 100 & $5 / 1994$ \\
\hline 200 & $9 / 2002$ \\
\hline 300 & $1 / 2011$ \\
\hline 400 & $5 / 2019$ \\
\hline
\end{tabular}
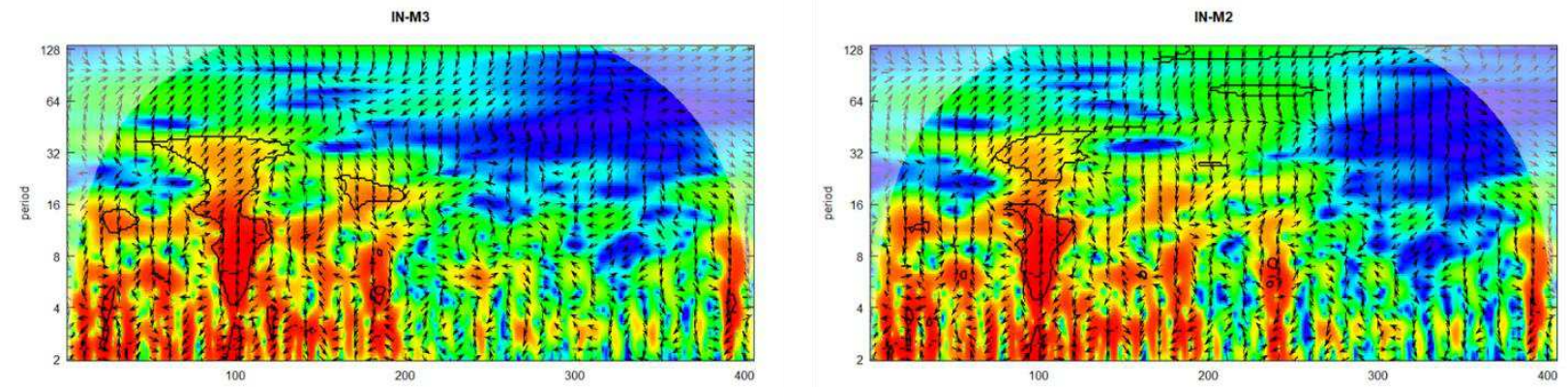

Fig. 4. Cross wavelet transform between money growth and inflation Note:5\% significance level against red noise designates by the contour, the lighter shade shows the cone of influence, by using phase randomised surrogate series is estimated from Monte Carlo simulations. The power colour code ranges from blue (low power) to red (high power). Arrows represent phase differences.

In some frequencies and times, it can be observed that inflation is leading while money supply growth is lagging, which could be explained by Demand-pull theory This suggests that aggregate demand increases more than the economy's productive capacity, which causes prices and wages to increase and forces the central bank to increase the money supply.

To analyse the correlation between the variables, we employ wavelet coherence with a phase difference to capture the nature of the relationship between inflation and money supply. Fig. 5 presents the wavelet coherence for the variables of the study. For the relationship between the INF-M1 pair, it can be seen in Fig. 5 many plot regions are showing the significant relationship between inflation and money supply. For example, from 1987 to1994 (up to frequency 7) there is generally a positive relationship between inflation and money supply, while from period 8 cycle to 16 cycles there is largely a negative relationship (the arrows point to the left). In Fig 5., it can be seen from 1995 to 2019, and there is a negative relationship between inflation and M1 at either high or low frequency (out of phase).

The results for the IN-M1 pair confirm the modern quantity theory regarding the existing relationship between money supply and inflation. These results (1987 to 1994) are in line with Abdullah et al. (2020) and Jiang et al. (2015), who found a positive relationship between money supply and inflation in the short run. However, the results are conflicting 
after 1995, as the change in the nature of the relationship to negative may reflect the different policy that was followed after the currency crisis in 1994.

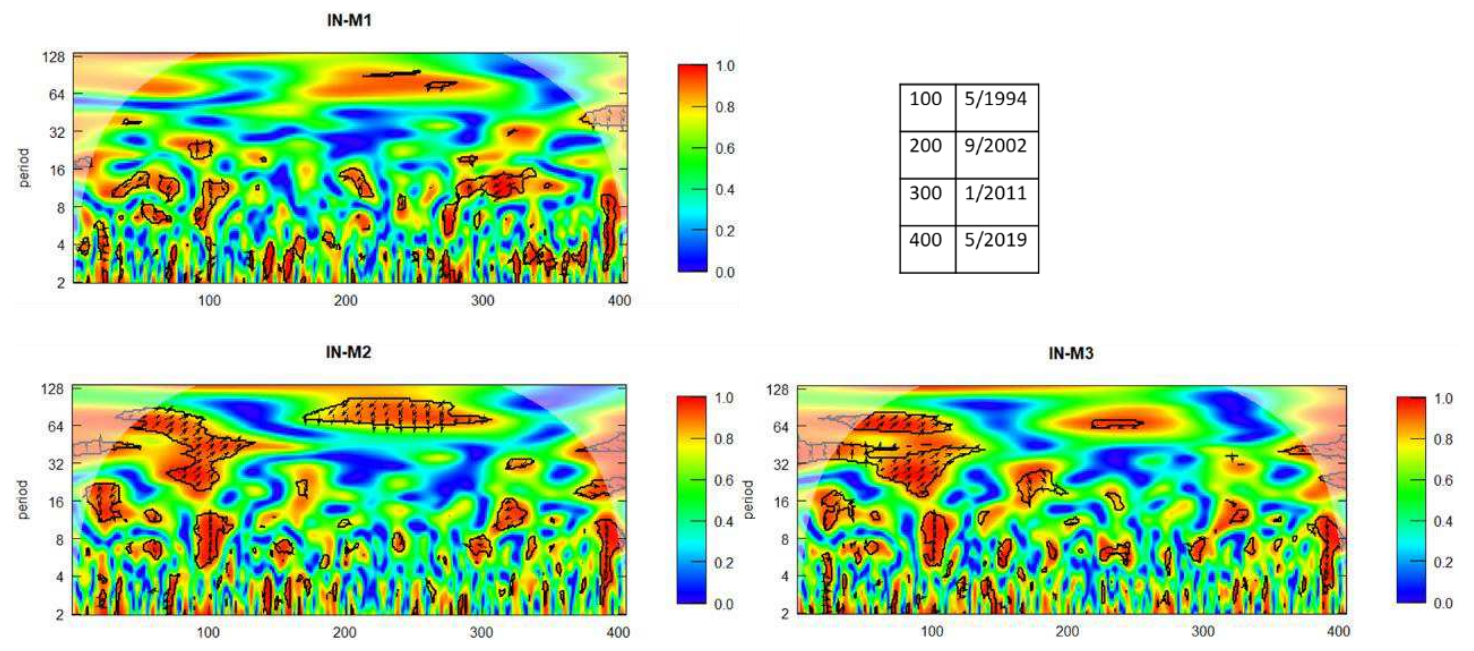

Fig. 5. Wavelet coherence between money growth and selected inflation. Note:5\% significance level against red noise designates by the contour, the lighter shade shows the cone of influence, by using phase randomised surrogate series is estimated from Monte Carlo simulations. The power colour code ranges from blue (low power) to red (high power). Arrows represent phase differences.

For the INF-M2 and INF-M3 pairs, it can be observed that the relationships are similar and almost similar to the pair INF-M1, although the association between INF-M2 and INF-M3 is stronger at low frequency (around 25 months to 120 months), the correlation between money supply growth and inflation almost up to 1, and there are two sizeable significant plot regions. The first plot regions show a positive relationship while the second one shows a negative relationship.

This result confirms both the traditional and modern quantity theories. It agrees on the existing relationship in the long run. Although there are arguments about the relationship in the short-run while there is an agreement between each of the traditional quantity theory of money and the modern quantity theory of money about the existing relationship between money supply and inflation in the long-run (Jiang et al., 2015, P 250). The results from the INF-M1 and INF-M2 pairs until the mid-1990s agree with both Abdullah et al. (2020) and Nguyen (2015) with an existing relationship in the short run. Although our results agree with those of Rua (2012), who argued that the relationship becomes stronger in the long run (low frequency), the sign of the relationship differs in the long run compared to the short run. Also, after the 1990s, it still agrees with Rua (2012) that the relationship becomes stronger in the long term. The results are following both Vladova and Yanchev (2015) and Su et al. (2016) that there is a two-way relationship between inflation and money supply. 


\section{Conclusion}

This paper has investigated the relationship between inflation and growth in money supply (M1, M2, M3) during the period from 1987 to 2019 at different time scales and attempted to provide an insight into the nature of the relationship between them. The study employed continuous wavelet transform to capture important information in terms of frequency and also used cross wavelet and different phases analysis to determine the lead-lag relationship. Wavelet coherence was also adopted to describe the association between the study variables.

Generally, the results confirm the modern quantity theory of money about the existing relationship between inflation and money supply in both the short run and long run. They also confirm the traditional quantity theory of money to the exact relationship in the long run. They are in complete agreement with the findings of Su et al. (2016) study that the money supply has a positive and negative impact on inflation in several sub-periods and vice versa. It appears that the changeable impact and lead-lag relationship between the variables are connected with different policies implemented after each crisis that occurred in Turkey.

Since the relation between money supply and inflation changeable, the study shows that the lead-lag can be changeable between money supply and inflation. The study suggests that sub-period analysis should be conducted to investigate money supply and inflation for each crisis, and it should handle the policies followed by authorities for each crisis.

\section{Availability of the data and materials}

The data for the variables of this study were collected from the Central Bank of the Turkish Republic.

\section{Funding}

Not applicable.

\section{Ethics approval and consent to participate}

The author is approving the article for ethical issues and consent to participate in the article.

\section{Authors' contributions}

We would like to state that all the authors are equally contribute the concern article.

\section{Consent for publication}

We would be willing to permit the Journal of Economic Structure to publish our article.

\section{Acknowledgements}

We are hugely thankful to the Editor and the Anonymous Referees for their most valuable suggestions that improved the early version of the manuscript. 


\section{Reference}

Abdullah, A.-M., Al-Abduljader, S., \& Naser, K. (2020). Determinants of Inflation in Kuwait1. The Journal of Developing Areas, 54(3).

Bankası, T. C. M. (2005). Enflasyon Hedeflemesi Rejiminin Genel Çerçevesi ve 2006 Yilında Para ve Kur Politikası. TCMB Basm Duyurusu, 56.

Celasun, O. (1999). The 1994 currency crisis in Turkey. The World Bank.

Ditimi, A., Sunday, K., \& Emma-Ebere, O. O. (2017). The Upshot of Money Supply and Inflation in Nigeria. Valahian Journal of Economic Studies, 8(2), 75-90.

DURMUŞ, H. (2018). TÜRKIYE'DE ENFLASYON HEDEFLEMESİ: ÖRTÜK ENFLASYON VE AÇIK ENFLASYON DÖNEMLERI ÜZERİNE BİR DEĞERLENDİRME. SIIIRT ÜNIVERSITTESI SOSYAL BILLIMLER ENSTITÜSÜ DERGISİ, 6(11), 181-201.

Friedman, M. (1968). The Role of Monetary Policy," American Economic Review, 58. Repr. in M. Friedman (1969), 102-110.

Gençay, R., Selçuk, F., \& Whitcher, B. J. (2001). An introduction to wavelets and other filtering methods in finance and economics. Elsevier.

Grinsted, A., Moore, J. C., \& Jevrejeva, S. (2004). Application of the cross wavelet transform and wavelet coherence to geophysical time series. Nonlinear Processes in Geophysics, 11(5/6), 561-566.

In, F., \& Kim, S. (2013). An introduction to wavelet theory in finance: a wavelet multiscale approach. World scientific.

Jeet, P., \& Vats, P. (2017). Learning Quantitative Finance with R. Packt Publishing Ltd.

Jiang, C., Chang, T., \& Li, X.-L. (2015). Money growth and inflation in China: New evidence from a wavelet analysis. International Review of Economics \& Finance, $35,249-261$.

Kayıkçı, F., \& Kaplan, S. (2019). Inflation Targeting in Turkey. Theoretical Economics Letters, 9(07), 2217.

King, M. (2001). No money, no inflation The role of money in the economy. Économie Internationale, (4), 111-131.

Koyuncu, A. F. T. (2014). Causality network between budget deficit, money supply and inflation: An application to Turkey. International Journal of Business and Social Science, 5(10).

Loh, L. (2013). Co-movement of Asia-Pacific with European and US stock market returns: A cross-time-frequency analysis. Research in International Business and Finance, 29, 1-13.

Mavikela, N., Mhaka, S., \& Phiri, A. (2019). The inflation-growth relationship in SSA inflation-targeting countries. Studia Universitatis Babes-Bolyai Oeconomica, 64(2), 84-102. 
Meyer, L. H. (2001). Does money matter. Federal Reserve Bank of St. Louis Review, 83 (September/October 2001).

Nguyen, B. (2015). Effects of fiscal deficit and money M2 supply on inflation: Evidence from selected economies of Asia. Journal of Economics, Finance and Administrative Science, 20, 49-53.

Özmen, M. U., \& Yılmaz, E. (2017). Co-movement of exchange rates with interest rate differential, risk premium and FED policy in "fragile economies." Emerging Markets Review, 33, 173-188.

Randy, K. Y., \& Young, K. (1993). Wavelet Theory and Its Application. Kluwer Academic, Dordrecht.

Rösch, A., \& Schmidbauer, H. (2016). WaveletComp 1.1: A guided tour through the $\mathrm{R}$ package. URL: Http://Www. Hsstat. Com/Projects/WaveletComp/WaveletComp_guided_tour.Pdf.

Rua, A. (2012). Money growth and inflation in the euro area: A time-frequency view. Oxford Bulletin of Economics and Statistics, 74(6), 875-885.

Sasongko, G., \& Huruta, A. D. (2018). Monetary policy and the causality between inflation and money supply in Indonesia. Business: Theory and Practice, 19, 8087.

Strano, A. (2003). Money Supply and Inflation How and how much can the Money Supply affect the Inflation Rate?”.

Su, C., Fan, J., Chang, H., \& Li, X. (2016). Is there causal relationship between money supply growth and inflation in China? Evidence from quantity theory of money. Review of Development Economics, 20(3), 702-719.

Torrence, C., \& Webster, P. J. (1998). The annual cycle of persistence in the El Nño/Southern Oscillation. Quarterly Journal of the Royal Meteorological Society, 124(550), 1985-2004.

Tursoy, T. (2019). Financial Stability and Financial Markets: Case of Turkey. University Library of Munich, Germany.

Veleda, D., Montagne, R., \& Araujo, M. (2012). Cross-wavelet bias corrected by normalizing scales. Journal of Atmospheric and Oceanic Technology, 29(9), 14011408.

Vladova, Z., \& Yanchev, M. (2015). Empirical Evidence on the Relationship between money supply dynamics and prices in Bulgaria. Bulgarian National Bank, Discussion Papers DP/10O. 


\section{Appendix}

\section{Appendix A}

Fig. 1.

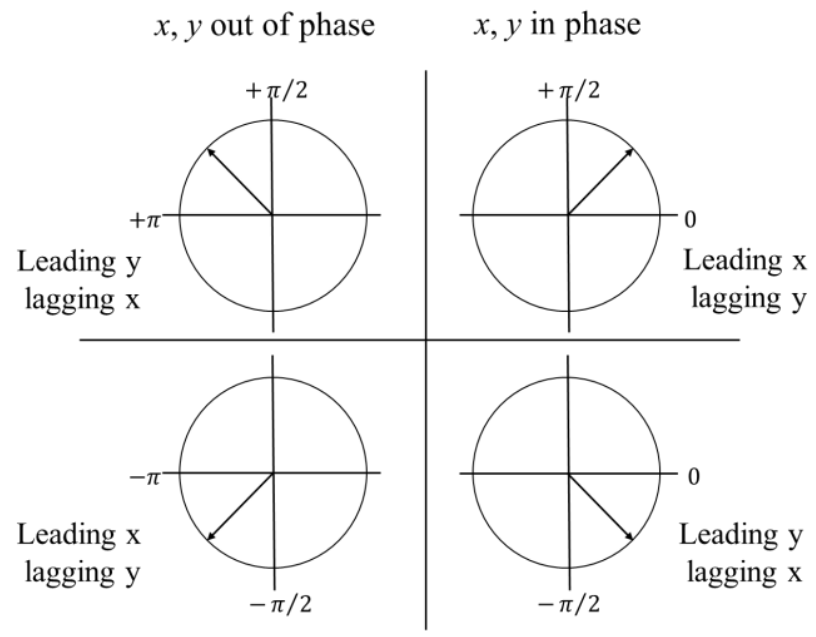

Based on Rösch \& Schmidbauer (2016)

\section{Appendix B}

Fig.2
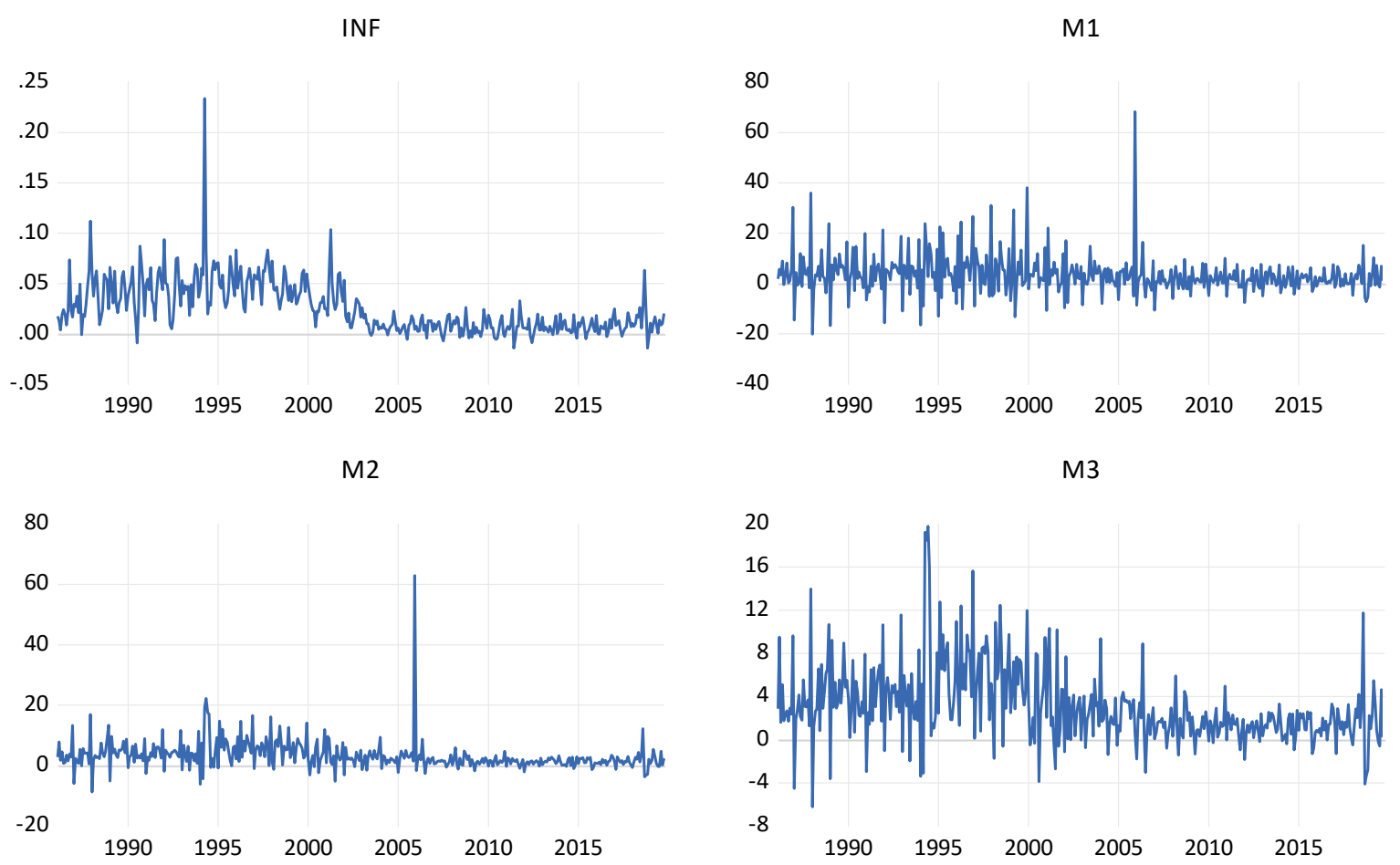
Appendix C

\begin{tabular}{|c|c|c|c|c|c|c|c|c|}
\hline $\begin{array}{c}\text { variabl } \\
\mathbf{e}\end{array}$ & mean & sd & $\begin{array}{c}\text { media } \\
\mathbf{n}\end{array}$ & min & max & range & skew & $\begin{array}{c}\text { kurtosi } \\
\text { S }\end{array}$ \\
\hline INF & 0.03 & 0.03 & 0.02 & -0.01 & 0.23 & 0.25 & 1.93 & 9.94 \\
\hline M1 & 3.39 & 7.98 & 2.38 & -20.19 & 68.2 & 88.39 & 2.03 & 12.38 \\
\hline M2 & 3.26 & 4.88 & 2.39 & -8.75 & 62.94 & 71.69 & 5.14 & 54.68 \\
\hline M3 & 3.08 & 3.55 & 2.28 & -624 & 19.79 & 26.3 & 1.34 & 3.29 \\
\hline
\end{tabular}

